\title{
From cold to hot: Climatic effects and productivity in Wisconsin dairy farms
}

\author{
L. Qi, ${ }^{*}$ B. E. Bravo-Ureta, ${ }^{*} \dagger^{1}$ and V. E. Cabrerał \\ *Department of Agricultural and Resource Economics, University of Connecticut, Storrs 06268 \\ tDepartment of Agricultural Economics, University of Talca, Talca 3460000, Chile \\ ‡Department of Dairy Science, University of Wisconsin-Madison, Madison 53706
}

\begin{abstract}
This study examined the effects of climatic conditions on dairy farm productivity using panel data for the state of Wisconsin along with alternative stochastic frontier models. A noteworthy feature of this analysis is that Wisconsin is a major dairy-producing area where winters are typically very cold and snowy and summers are hot and humid. Thus, it is an ideal geographical region for examining the effects of a range of climatic factors on dairy production. We identified the effects of temperature and precipitation, both jointly and separately, on milk output. The analysis showed that increasing temperature in summer or in autumn is harmful for dairy production, whereas warmer winters and warmer springs are beneficial. In contrast, more precipitation had a consistent adverse effect on dairy productivity. Overall, the analysis showed that over the past $17 \mathrm{yr}$, changes in climatic conditions have had a negative effect on Wisconsin dairy farms. Alternative scenarios predict that climate change would lead to a 5 to $11 \%$ reduction in dairy production per year between 2020 and 2039 after controlling for other factors.
\end{abstract}

Key words: climatic effect, dairy production, stochastic production frontiers, Wisconsin

\section{INTRODUCTION}

There is increasing concern about the effect of climate change on food security and agricultural sustainability among policy makers and public interest groups. The US Environmental Protection Agency (US EPA, 2013) reports that global surface air temperature over land and oceans has risen steadily over the last $100 \mathrm{yr}$, and extreme weather events have become routine. Climatic factors, such as temperature and rainfall, have a strong effect on agricultural output (IPCC, 2014), which induces adaptation strategies that can lead to structural changes in farming (Mendelsohn et al., 1994).

Received March 5, 2015

Accepted August 27, 2015.

${ }^{1}$ Corresponding author: boris.bravoureta@uconn.edu
Farming, which contributes at least $\$ 395$ billion to the US economy per year (USDA NASS, 2012), is more sensitive and vulnerable to climate change than other sectors (IPCC, 2014). Livestock production is particularly vulnerable to hot weather, especially in combination with high humidity, which can lead to significant losses in productivity and, in extreme cases, to animal death (Mader, 2003). Besides direct effects on animals, climatic conditions also affect feed supplies by influencing the growth of silage and forage (Hill et al., 2004). Comprehensive analyses of the connection between climatic effects and farm productivity are of increasing importance.

The focus of our paper is dairy farming, which is the fourth largest agricultural subsector in the United States. There is a significant body of animal and dairy science literature, briefly reviewed below, that clearly establishes the susceptibility of dairy cows to extreme weather conditions (IPCC, 2014). The economic literature on this subject remains quite limited; hence, an important motivation for this research is the need to introduce climatic effects into milk production models to evaluate potential economic effects.

In general, research on the connection between climatic variables and livestock has focused on outputrelated effects. Dairy cattle experience stress when the temperature is out of the thermo-neutral zone (West, 2003; Allen et al., 2013). When heat or cold stress requires the cow to increase the amount of energy used to maintain body temperature, less energy is available for milk production (Collier et al., 2011). The thermoneutral zone is between 5 and $25^{\circ} \mathrm{C}$ and depends on many factors, such as age, breed, feed intake, diet, current milk production level, and housing (Roenfeldt, 1998). Under the same housing conditions, the comfort zone of European cattle was found to be between -1.11 and $15.6^{\circ} \mathrm{C}$, whereas for Indian cattle this zone was found to be between 10 and $26.7^{\circ} \mathrm{C}$. Temperatures outside of the thermo-neutral zone have adverse effects on livestock productivity (Brody, 1956; Kadzere et al., 2002; Nardone et al., 2010).

Heat stress, which is much more likely to occur in lactating cows during hot and humid summer days, is 
not only related to temperature but also to air humidity, and it affects the capacity of the cow to dissipate heat. Heat stress affects feed intake, feed efficiency, milk yield, reproductive efficiency, cow behavior, and disease incidence (Cook et al., 2007; Tucker et al., 2007; Rhoads et al., 2009). It is estimated that the DMI decreases by up to $40 \%$ when the ambient temperature is $40^{\circ} \mathrm{C}$ (NRC, 2001).

Cold stress is another climatic element that reduces output in some areas. At low temperatures, more dietary energy is needed for cows to maintain body temperature. Cold stress causes animals to consume more feed but to produce less milk, and it also increases milk fat content (Young, 1981). In comparison to heat stress, cold stress is more restricted geographically and can have a significant incidence in the northern United States during winter months.

Climatic conditions have a strong effect on livestock productivity generally and on the dairy sector in particular. A significant negative correlation has been noted between DMI and the temperature-humidity index (THI), where the latter is a measure of heat stress often used by animal scientists (Holter et al., 1996; Kadzere et al., 2002). Consequently, a negative correlation exists between THI and milk yield. For example, Key and Sneeringer (2014) and Mukherjee et al. (2013) incorporated annual average THI in production frontier models and found a significant negative effect on milk production. St-Pierre et al. (2003) documented that heat stress affects livestock in all continental US states, although with considerable spatial variation. They estimated that total losses would add up to about $\$ 900$ million/yr ( $\$ 100 /$ cow per year) even when heat abatement systems were in place. The loss would be as high as $\$ 1.5$ billion/yr ( $\$ 167 /$ cow per year) without abatement systems. Seo and Mendelsohn (2008) showed that changing livestock species and numbers is one option that farmers have to adapt to climate change.

Dairy production is influenced by temperature and precipitation, and these variables can have divergent effects in different seasons. The literature reveals a variety of methods to measure and incorporate climatic effects in crop and livestock farming (e.g., Mendelsohn et al., 1994; Kelly et al., 2005; Schlenker et al., 2006; Deschenes and Greenstone, 2007; Mukherjee, 2012). These studies usually use temperature, precipitation, and, in some cases, heat degree-days to reflect climatic effects on agricultural production.

Our analysis adopts seasonal averages for temperature and precipitation to capture the climatic effects. Using temperature and precipitation directly, instead of an index such as THI, allows for a clear interpretation of the climatic effects on the dependent variable of interest. In addition, we redefined the length of each season according to the monthly average temperature in the state of Wisconsin.

Wisconsin is one of the largest dairy producing areas in the United States. According to the National Agricultural Statistics Service (http://quickstats.nass.usda. gov/), total milk production in Wisconsin was 27,572 million pounds in 2013, accounting for nearly $14 \%$ of the US total milk output. In the same year, the total number of milk cows was 1.271 million.

The general objective of our study was to contribute to the understanding of the effects of climatic variables on dairy farm productivity. The specific objectives were to use alternative stochastic frontier panel data models to analyze the relationship between dairy productivity and climatic effects using data for the state of Wisconsin. The specification of our model makes it possible to calculate a total annual climatic effect as well as partial effects for temperature and precipitation and jointly for all seasons. This specification is a novel contribution to the dairy productivity literature. Based on the estimation results, this study predicts the effects of alternative future climate change scenarios on dairy farms. A noteworthy feature of the current paper is that Wisconsin is a significant dairy producing state in the United States, where winters can be very cold and snowy and summers hot and humid. These extremes are ideal to explore the effects of a range of climatic factors on dairy production.

\section{MATERIALS AND METHODS}

\section{Data}

The data used for empirical estimation was derived from 2 sources. First, the input-output data contains a total of 9,437 observations for 958 dairy farms scattered around 52 Wisconsin counties over the 17 -yr period from 1996 to 2012. These data consist of detailed information of dairy farms participating in the Agricultural Financial Advisor (AgFA; http://cdp.wisc.edu/agfa. htm) program at the University of Wisconsin-Madison Center for Dairy Profitability (https://cdp.wisc.edu). The aim of the AgFA program is to collect, analyze, and store high-quality financial and production information for dairy farms in the state of Wisconsin (Cabrera et al., 2010). Second, the temperature and precipitation data were obtained from the Parameter-Elevation Regressions on Independent Slopes Model (PRISM) maps (http://www.prism.oregonstate.edu/recent/). We used Geographic Information System (GIS) techniques to generate monthly mean temperature and precipitation for each county and year. The 2 data sets (input-output 
and climate) were merged based on county and year identifiers. Thus, in our analysis, all farms within a county shared the same climatic data.

The data for expected future climatic conditions for our simulations was generated by the National Center for Atmospheric Research (NCAR) GIS program for the fourth Assessment Report of the Intergovernmental Panel on Climate Change (IPCC). The NCAR data set includes monthly temperature and precipitation projections over the period from 2000 to 2099 for 4 IPCC scenarios (https://gisclimatechange.ucar.edu/). This study focuses on 2 of the scenarios over the nearterm projection period, namely years 2020 to 2039 . One is the commitment (CMT) scenario, which assumes that the concentration of pollutants in the atmosphere is held at 2000 levels. This scenario denotes moderate climate change. The second is the high A2 (HA2) scenario, which assumes that the world undergoes high population growth, moderate gross domestic product growth, high energy use, medium-high land use changes, low resource availability (mainly oil and gas), and slow technological change. Based on these emission scenarios, NCAR combines integrated assessment models, carbon-cycle models, general circulation models, and earth system models, to calculate precipitation and surface temperature for each scenario.

According to monthly mean temperatures (Table 1), our study redefined the seasons in Wisconsin as follows: summer $=$ June through September; autumn $=$ October and November; winter = December, January, February, and March; and spring = April and May. Based on this definition, the average temperature in winter is around $-4^{\circ} \mathrm{C}$, and the average temperature in summer is around $19^{\circ} \mathrm{C}$ (Figure 1). Average precipitation in spring and summer is greater than in autumn and winter. The average monthly precipitation in spring (including April and May) was $14.5 \mathrm{~cm}$ in 2004, which was the highest recorded for all seasons and all years included in this study (Figure 2). We compared our climatic data with the National Oceanic and Atmospheric Administration (NOAA) climatic records (http://www.ncdc.noaa. gov/cdo-web/), which are collected from land-based weather stations located in the 10 Wisconsin counties included. We found no significant differences between the values across these 2 data sets, except for a small difference in the average temperature in winter, which was slightly lower in the NOAA data set. For the nearterm period (2020-2039), the expected average seasonal temperature, especially in the summer, was higher than for the period from 1996 to 2012 (Figure 3). Average temperature in winter was $-4^{\circ} \mathrm{C}$ in the CMT scenario and $-3^{\circ} \mathrm{C}$ in the $\mathrm{HA} 2$ scenario. Average temperature in summer was 21.06 and $22.07^{\circ} \mathrm{C}$ in the CMT and HA2 scenarios, respectively. In terms of precipitation,
Table 1. Descriptive statistics for monthly mean temperature ${ }^{1}\left({ }^{\circ} \mathrm{C}\right)$ in 10 Wisconsin counties: 1996-2012

\begin{tabular}{|c|c|c|c|c|}
\hline Season $^{2}$ & Mean & SD & Minimum & Maximum \\
\hline \multicolumn{5}{|l|}{ Winter } \\
\hline December $^{3}$ & -4.60 & 3.17 & -14.66 & 0.14 \\
\hline January & -7.57 & 3.13 & -16.43 & 0.17 \\
\hline February & -5.31 & 3.08 & -13.38 & 1.21 \\
\hline March & 0.30 & 2.88 & -7.52 & 8.26 \\
\hline \multicolumn{5}{|l|}{ Spring } \\
\hline April & 7.25 & 1.55 & 1.14 & 10.49 \\
\hline May & 13.06 & 1.86 & 7.71 & 16.66 \\
\hline \multicolumn{5}{|l|}{ Summer } \\
\hline June & 18.66 & 1.19 & 15.17 & 21.99 \\
\hline July & 21.44 & 1.65 & 15.87 & 24.88 \\
\hline August & 20.33 & 1.36 & 15.01 & 22.29 \\
\hline September & 16.11 & 1.44 & 11.33 & 19.17 \\
\hline \multicolumn{5}{|l|}{ Autumn } \\
\hline October & 9.32 & 1.72 & 3.44 & 13.22 \\
\hline November & 2.70 & 2.30 & -4.88 & 7.88 \\
\hline
\end{tabular}

${ }^{1}$ Data source: http://www.prism.oregonstate.edu/recent/.

${ }^{2}$ Season: this study redefines the length of each season according to the monthly average temperature; spring = April and May; summer $=$ June through September; autumn $=$ October and November; and winter $=$ December, January, February, and March.

${ }^{3}$ The climatic data are at the county level and are merged with the farm input-output data based on county and year identifiers. The values are aggregates for the 10 counties where the 54 farms are located. Thus, all farms within a county and a given year share the same climatic data.

the average projection under the CMT scenario for the period from 2020 to 2039 was $6.63 \mathrm{~cm}$ in spring, 5.15 $\mathrm{cm}$ in summer, $5.04 \mathrm{~cm}$ in autumn, and $5.51 \mathrm{~cm}$ in winter. Under the HA2 scenario, the average precipitation was $6.08 \mathrm{~cm}$ in spring, $4.68 \mathrm{~cm}$ in summer, $4.65 \mathrm{~cm}$ in autumn, and $5.54 \mathrm{~cm}$ in winter (Figure 4).

Considering that the structure of the panel was unbalanced, several options exist to configure the data, ranging from including all observations to a balanced panel. In the current study, we used the balanced panel conformed by 54 farms located across 10 counties, which gave a total of 918 observations over the 17-yr period (1996-2012). Descriptive statistics for output, inputs, and climatic variables are presented in Table 2. The total milk equivalent produced by the average farm in the data set was 1,222 t/yr. Milk equivalent units are equal to total farm income per year divided by the average annual US milk price for the time period in question. Total milk equivalent was used because all inputs in the data set correspond to the total amount used by the whole farm; thus, this approach makes it possible to have all variables in the model measured consistently. It is important to stress that the farms in our data set were highly specialized in milk production, where the overall average milk revenues as percent of total farm income is $82 \%$.

Table 2 shows average annual input use per farm at 98 cows, $6,320 \mathrm{~h}$ of labor, $610 \mathrm{t}$ of concentrate feed, 


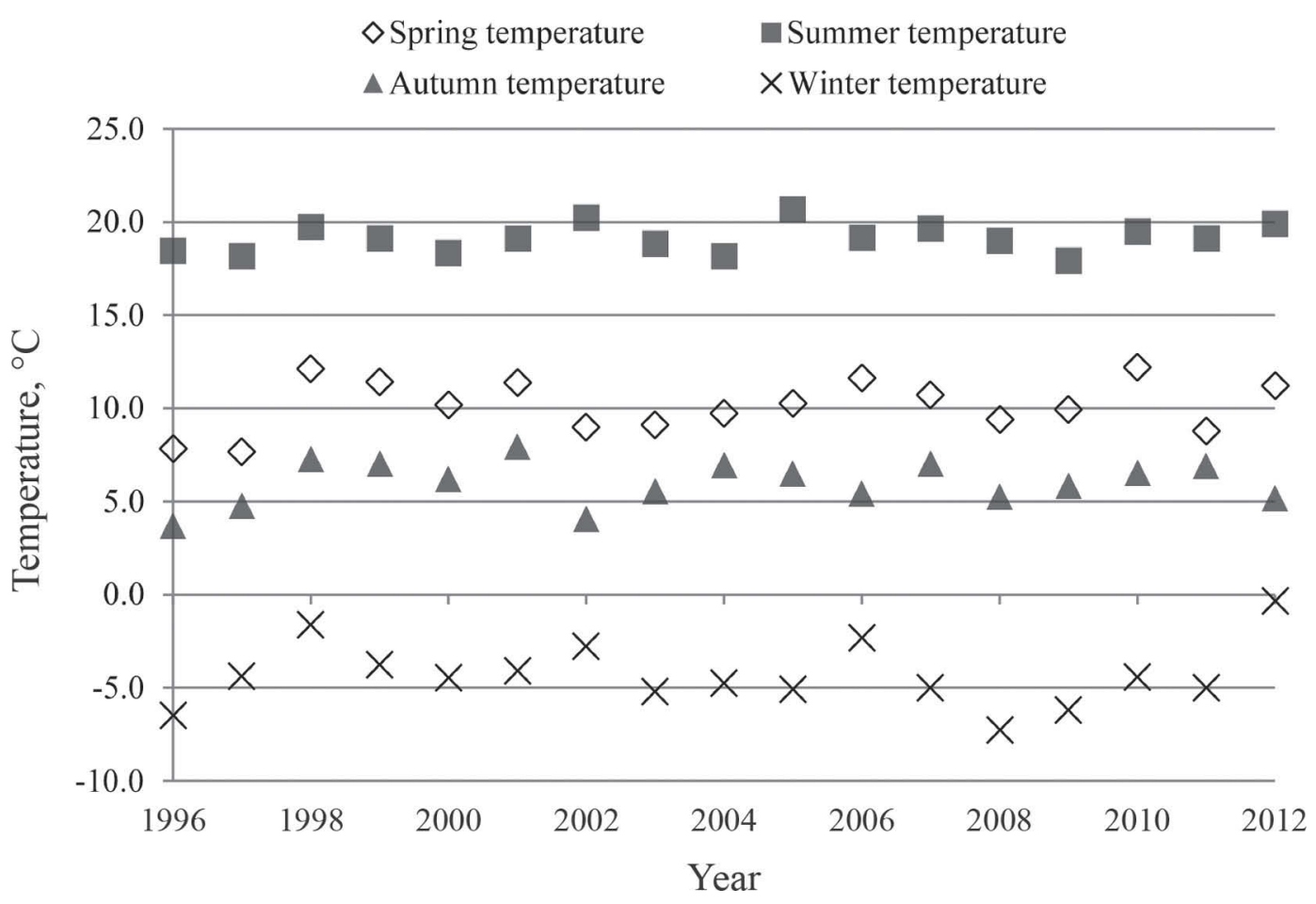

Figure 1. Annual seasonal average temperature for 10 Wisconsin counties: 1996-2012. Seasons were defined as spring = April and May; summer = June through September; autumn = October and November; and winter = December, January, February, and March. Data source: http://www.prism.oregonstate.edu/recent/.

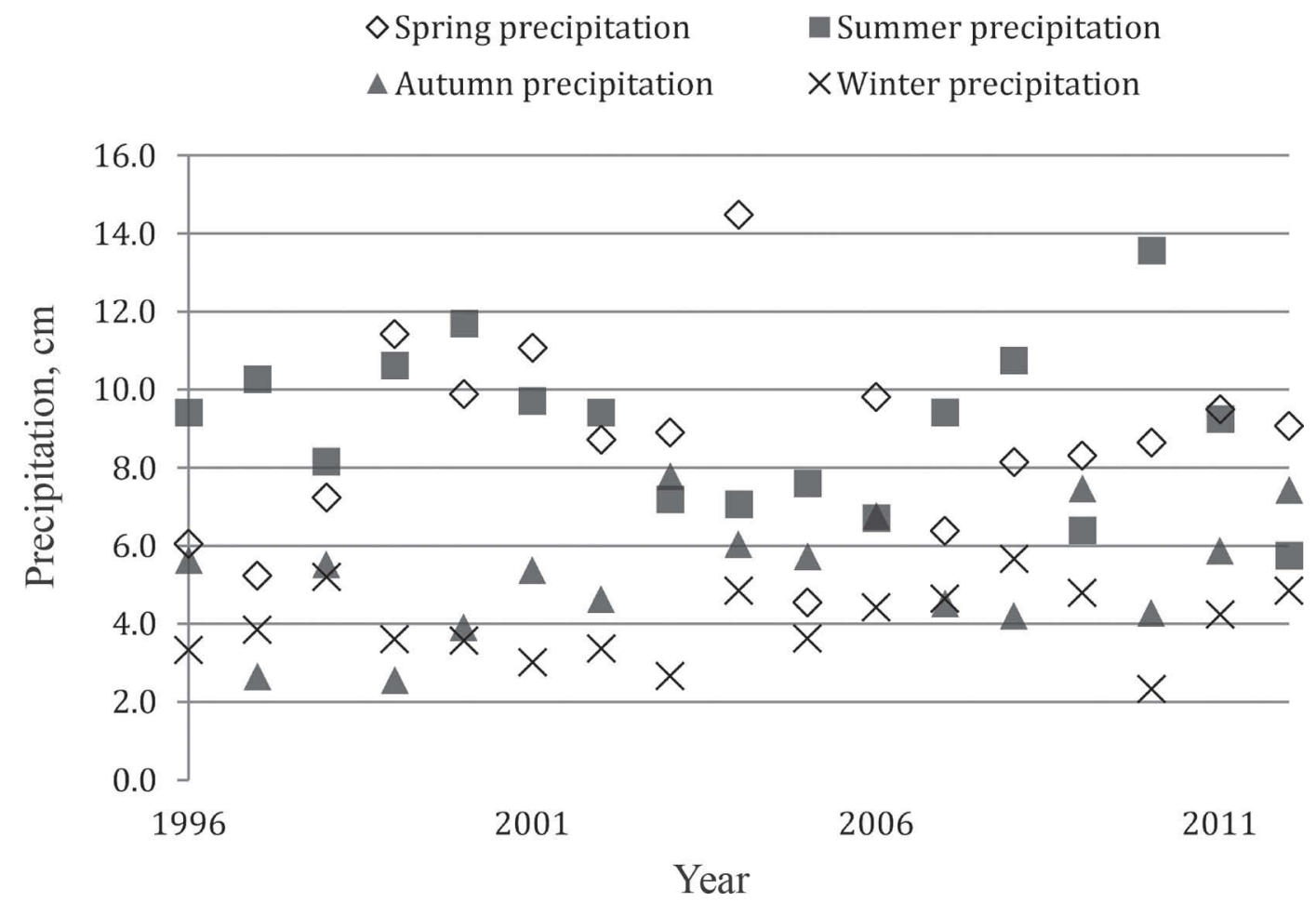

Figure 2. Annual seasonal average precipitation for 10 Wisconsin counties: 1996-2012. Seasons were defined as spring = April and May; summer $=$ June through September; autumn $=$ October and November; and winter $=$ December, January, February, and March. Data source: http://www.prism.oregonstate.edu/recent/. 
$\$ 80,513$ (2012 dollars) in depreciation, $\$ 34,918$ (2012 dollars) in animal expenses, and $\$ 86,907$ (2012 dollars) in crop expenses. We should note that, according to National Agricultural Statistics Service, between 1996 and 2012 the average number of milk cows in a Wisconsin dairy farm was 61 , which is lower than the 98 cows in our data. This difference is likely due to the tendency of larger farms to enroll in programs such as AgFA.

Labor denotes the total hours of family paid and unpaid labor and management as well as hired workers. Concentrate feed is the total amount of $16 \%$ protein dairy ration purchased per year. Depreciation denotes the capital use per year, which includes depreciation on breeding livestock, machinery, equipment, and buildings. Animal expense includes the total expenditure of veterinary and medicine, breeding fees, and other livestock expenses. Crop expenses are composed of fertilizer and other chemical inputs, seeds and plants, gas and fuel, rented machinery, and other crop expenses. Given that we do not have data on hay, we used crop expenses to capture this input. In addition, including land as well as crop expenses can lead to collinearity problems. Consistent with many papers, such as Lawson et al. (2004), Theodoridis and Psychoudakis (2008), Cabrera et al. (2010), and Moreira and Bravo-Ureta (2010), we found it more appropriate to include crop expenses in our model. Furthermore, we incorporated a time trend into the production frontier to reflect technological progress.

\section{Empirical Model}

Stochastic production frontiers (SPF) have been used widely for over $40 \mathrm{yr}$, and during this period many methodological innovations have been introduced (Fried et al., 2008), including the ability to account for unobserved heterogeneity (Greene 2005a,b; Abdulai and Tietje, 2007). Multiple authors have applied SPF to analyze productivity in dairy farming in a variety of settings (e.g., Battese and Coelli, 1988; Kumbhakar and Tsionas, 2006; Tauer and Mishra, 2006; Cabrera et al., 2010; Mayen et al., 2010; Moreira and Bravo-Ureta, 2010; Mukherjee et al., 2013; Njuki and Bravo-Ureta 2015). The SPF models are common in economic analy-

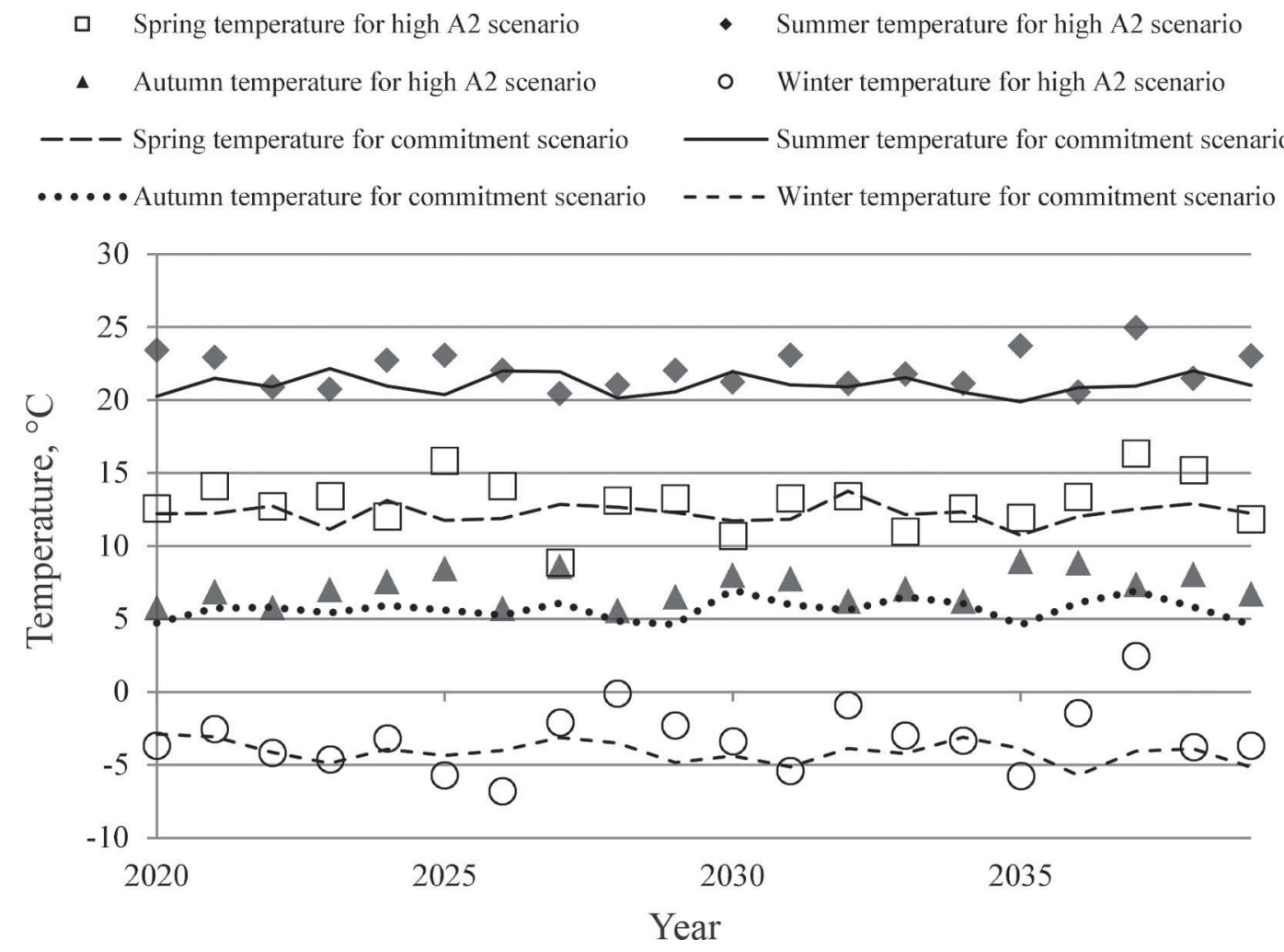

Figure 3. Seasonal average temperature of commitment and high A2 scenarios. Seasons were defined as spring = April and May; summer $=$ June through September; autumn = October and November; and winter = December, January, February, and March. Commitment scenario assumes that the concentration of pollutants in the atmosphere is held fixed at 2000 levels. High A2 scenario assumes that the world undergoes high population growth, medium gross domestic product growth, high energy use, medium-high land use changes, low resource availability (mainly oil and gas), and slow technological change. Data are derived from the National Center for Atmospheric Research (NCAR) GIS program (https://gisclimatechange.ucar.edu/). 
ses and researchers are now using them specifically to examine the relationship between climatic effects and productivity (Hughes et al., 2011; Dell et al., 2014; Njuki et al., 2015).

Here, we specify an SPF model to identify the effect of climatic conditions on output using a Cobb-Douglas functional form and alternative panel data formulations. According to Dell et al. (2014), panel data models such as the ones used in our paper, can "exploit the exogeneity of cross-time weather variation allowing for causative identification."

$\diamond$ Spring precipitation for high A2 scenario

- Spring precipitation for commitment scenario

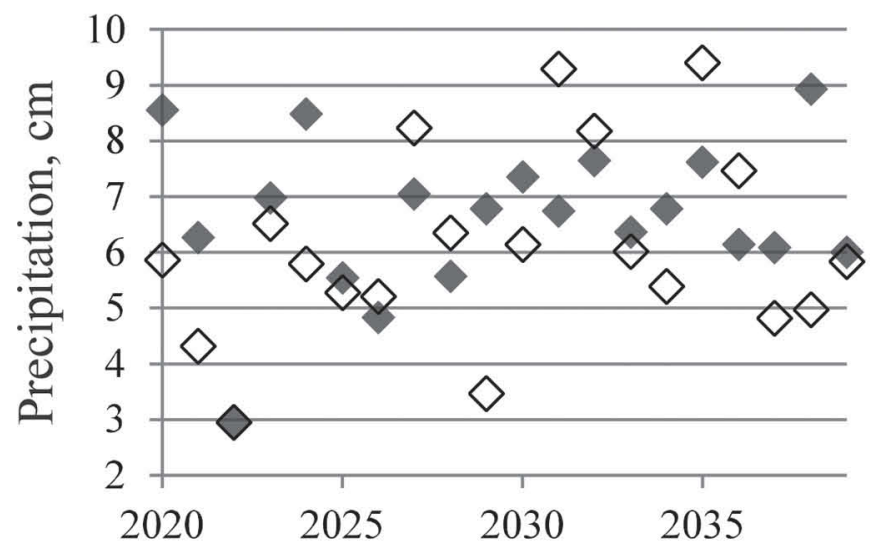

O Autumn precipitation for high A2 scenario

- Autumn precipitation for commitment scenario

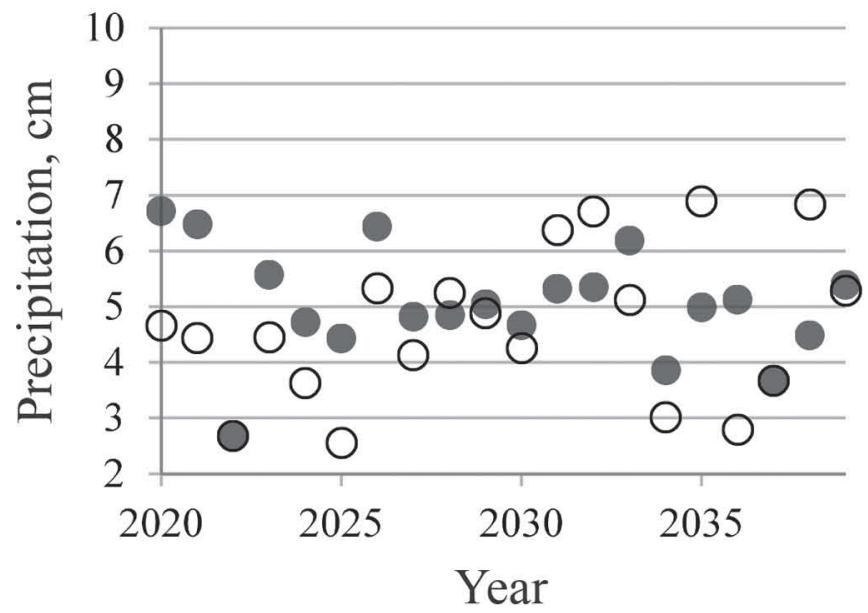

The basic SPF model can be written as:

$$
\begin{aligned}
& \ln Y_{i t}=\alpha+\sum_{k=1}^{6} \beta_{k} \ln X_{k i t}+ \\
& \sum_{s=1}^{8} \gamma_{s} Z_{s i t}+\theta_{1} T+\theta_{2} T^{2}+\nu_{i t}-\mu_{i t},
\end{aligned}
$$

where $Y_{i t}$ is output measured as milk equivalent for the $i$ th farm in period $t ; X_{k i t}$ is the $k$ th input; $Z_{s i t}$ is the sth climatic variable; and $T$ denotes the time trend. $\alpha$,

$\square$ Summer precipitation for high A2 scenario

Summer precipitation for commitment scenario

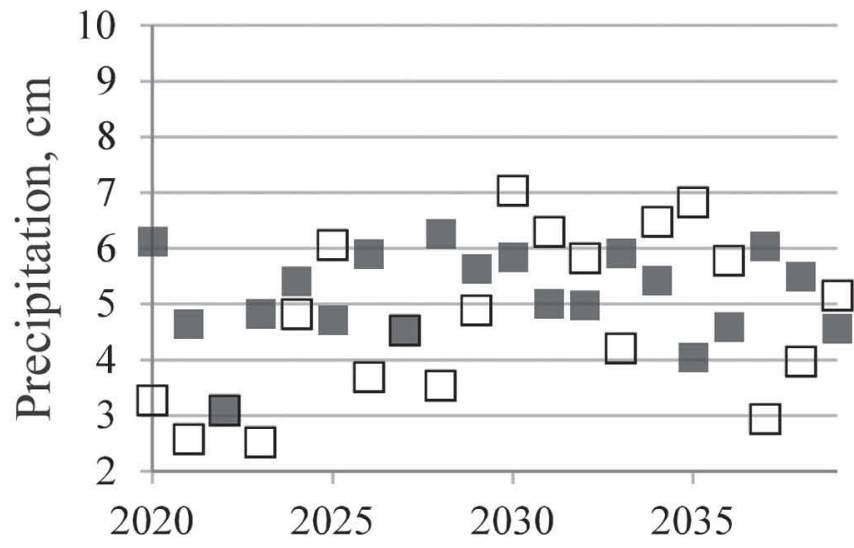

$\triangle$ Winter precipitation for high A2 scenario

$\Delta$ Winter precipitation for commitment scenario

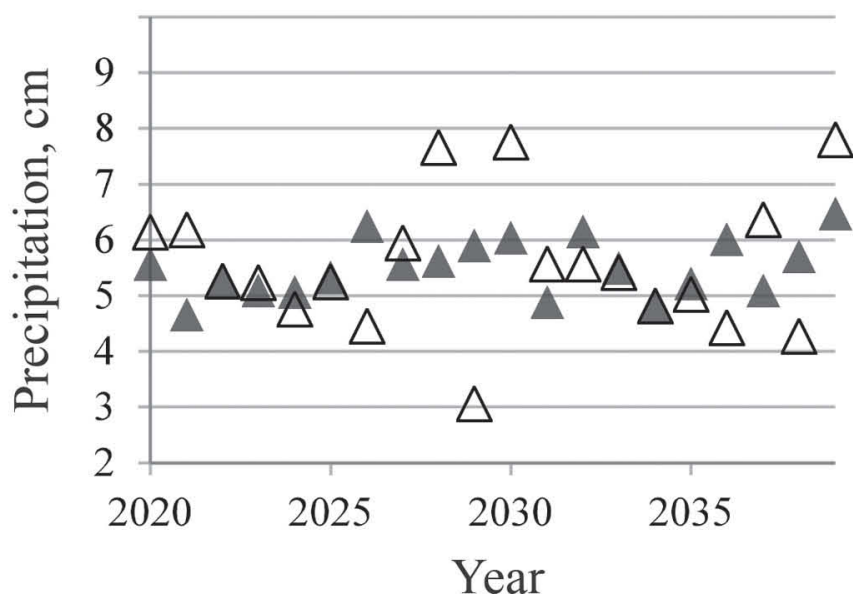

Figure 4. Seasonal average precipitation of commitment and high A2 scenarios. Seasons were defined as spring = April and May; summer $=$ June through September; autumn $=$ October and November; and winter $=$ December, January, February, and March. Commitment scenario assumes that the concentration of pollutants in the atmosphere is held fixed at 2000 levels. High A2 scenario assumes that the world undergoes high population growth, medium gross domestic product growth, high energy use, medium-high land use changes, low resource availability (mainly oil and gas), and slow technological change. The data are derived from National Center for Atmospheric Research (NCAR) GIS program (https://gisclimatechange.ucar.edu/). 
QI ET AL.

Table 2. Descriptive statistics for 54 Wisconsin dairy farms: 1997-2012 ${ }^{1}$

\begin{tabular}{|c|c|c|c|c|}
\hline Variable & Mean & $\mathrm{SD}$ & Minimum & Maximum \\
\hline \multicolumn{5}{|l|}{ Output/farm per year } \\
\hline Milk equivalent,${ }^{2} \mathrm{t}$ & 1,222 & 1,490 & 142 & 18,543 \\
\hline \multicolumn{5}{|c|}{ Conventional inputs/farm per year } \\
\hline Cow, ${ }^{3}$ head & 98 & 98 & 21 & 1,162 \\
\hline Labor, ${ }^{4} \mathrm{~h}$ & 6,320 & 6,391 & 1,298 & 69,686 \\
\hline Concentrate feed ${ }^{5} \mathrm{t}$ & 610 & 900 & 11 & 8,695 \\
\hline Depreciation, ${ }^{6} \$^{7}$ & 80,513 & 99,355 & 465 & $1,196,189$ \\
\hline Animal expenses, ${ }^{8} \$^{7}$ & 34,918 & 52,940 & 283 & 642,433 \\
\hline Crop expenses, ${ }^{9} \$^{7}$ & 86,907 & 76,434 & 2,666 & 979,827 \\
\hline Time trend & 9 & 5 & 1 & 17 \\
\hline \multicolumn{5}{|l|}{ Climatic variables } \\
\hline Spring temperature, ${ }^{10} \mathrm{C}^{\circ}$ & 10.15 & 1.47 & 5.37 & 12.71 \\
\hline Summer temperature, ${ }^{10} \mathrm{C}^{\circ}$ & 19.14 & 0.94 & 15.70 & 21.02 \\
\hline Autumn temperature, ${ }^{10} \mathrm{C}^{\circ}$ & 6.01 & 1.46 & 0.36 & 8.83 \\
\hline Winter temperature, ${ }^{10} \mathrm{C}^{\circ}$ & -4.29 & 2.08 & -10.87 & 0.73 \\
\hline Spring precipitation, ${ }^{11} \mathrm{~cm}$ & 8.67 & 2.61 & 3.89 & 16.11 \\
\hline Summer precipitation, ${ }^{11} \mathrm{~cm}$ & 9.00 & 2.30 & 4.87 & 18.69 \\
\hline Autumn precipitation, ${ }^{11} \mathrm{~cm}$ & 5.32 & 1.74 & 2.09 & 9.81 \\
\hline Winter precipitation, ${ }^{11} \mathrm{~cm}$ & 4.00 & 1.09 & 1.93 & 6.90 \\
\hline
\end{tabular}

${ }^{1}$ There are 918 observations included. Data source: Input-output data comes from the Agricultural Financial Advisor (AgFA; http://cdp.wisc.edu/agfa.htm) program from the University of Wisconsin-Madison Center for Dairy Profitability (https://cdp.wisc.edu). Climate data are from http://www.prism.oregonstate.edu/recent/.

${ }^{2}$ Total milk equivalent in metric tonnes per farm per year. It is equal to total farm income divided by the average farm level US milk price for the time period (year) in question.

${ }^{3}$ Number of adult cows.

${ }^{4}$ Family paid and unpaid labor and management and hired labor.

${ }^{5} 16 \%$ protein dairy concentrate feed.

${ }^{6}$ Depreciation on breeding livestock, machinery, equipment, and buildings.

${ }^{7}$ Deflated to 2012 dollars.

${ }^{8}$ Veterinary and medicine, breeding fees, and other livestock expense.

${ }^{9}$ Chemical, fertilizer, seeds and plants, gas and fuel, rented machinery, and other crop expense.

${ }^{10}$ Average value of monthly mean temperature for each season; spring = April and May; summer = June through September; autumn = October and November; and winter = December, January, February, and March.

${ }^{11}$ Average value of monthly precipitation for each season as just defined.

$\beta, \gamma$, and $\theta$ are parameters to be estimated. The component $\nu_{i t}$ has a symmetric normal distribution, and $\mu_{i t}$ follows a half-normal distribution. These 2 terms are assumed to be independent of each other. Thus, $\nu_{i t}$ denotes the variation from the frontier resulting from external events such as luck, and $\mu_{i t}$ captures technical inefficiency reflecting managerial ability. Technical efficiency $(\mathbf{T E})$ was calculated as $\mathrm{TE}=\exp \left(-\mu_{i t}\right)($ Battese and Coelli, 1992).

To examine the robustness of our analysis, we compared 5 alternative specifications of equation [1] (models 1 through 5 in the Appendix): model $1=$ pooled frontier without climatic variables; model $2=$ pooled frontier with climatic variables; model $3=$ "true" fixed effects (TFE) specification with climatic variables; model 4 = "true" random effects (TRE) specification with climatic variables; and model $5=$ "true" random effects model with Mundlak's specification (TRE-M) and climatic variables. Models 1 and 2 essentially treat the data as cross-sectional, whereas models 3 to 5 pro- vide a panel data treatment. Moreover, the TFE and TRE models capture time invariant heterogeneity along with time-variant technical efficiency (Greene 2005a, 2005b). The TFE model allows for correlation between the regressors and the heterogeneity term, but the TRE model assumes no correlation (Greene, 2005b), which is a potential shortcoming that can be addressed by the TRE-M model (Abdulai and Tietje, 2007). A battery of statistical tests was performed to determine the most robust model, which was then used to undertake a comprehensive efficiency and productivity analysis with emphasis on climatic effects.

According to Hughes et al. (2011), the climatic effect index (CEI) measures the joint effect of all climatic variables included in the production frontier on output. A CEI value greater than 1 means that climatic conditions are favorable, whereas the opposite is true when the CEI value is less than 1 . The total CEI for farm $i$ at time $t$, based on equation [1] and the estimated parameter $\hat{\gamma}$, can be written as 


$$
\mathrm{CEI}_{i t}=\exp \left(\sum_{s=1}^{8} \hat{\gamma}_{s} Z_{s i t}\right)
$$

In addition, the total $\mathrm{CEI}_{i t}$ in equation [2] can be decomposed into 6 partial indexes: CEI for temperature (CEIT); CEI for precipitation (CEIP); CEI for spring (CEISPR); CEI for summer (CEISUM); CEI for autumn (CEIAUT); and CEI for winter (CEIWIN). Both CEIT and CEIP reflect the total effect of temperature and precipitation respectively, whereas CEISPR, CEISUM, CEIAUT, and CEIWIN denote seasonal indexes. These partial CEI terms can be expressed as follows:

$$
\mathrm{CEIT}_{i t}=\exp \left(\sum_{s=1}^{4} \hat{\gamma}_{s} Z_{s i t}\right) \text { and } \mathrm{CEIP}_{i t}=\exp \left(\sum_{s=5}^{8} \hat{\gamma}_{s} Z_{s i t}\right),
$$

$$
\begin{aligned}
& \operatorname{CEISPR}_{i t}=\exp \left(\hat{\gamma}_{1} Z_{1 i t}+\hat{\gamma}_{5} Z_{5 i t}\right) ; \\
& \operatorname{CEISUM~}_{i t}=\exp \left(\hat{\gamma}_{2} Z_{2 i t}+\hat{\gamma}_{6} Z_{6 i t}\right) ; \\
& \mathrm{CEIAUT}_{i t}=\exp \left(\hat{\gamma}_{3} Z_{3 i t}+\hat{\gamma}_{7} Z_{7 i t}\right) ; \text { and } \\
& \text { CEIWIN }_{i t}=\exp \left(\hat{\gamma}_{4} Z_{4 i t}+\hat{\gamma}_{8} Z_{8 i t}\right)
\end{aligned}
$$

These 6 CEI terms provide a rich perspective for examining the climatic effects in dairy farming. We underscore that this analysis is a novel contribution of this paper to the dairy productivity literature.

To examine the relationship between milk output and the climatic effects, we hold the conventional inputs and the time trend at their mean values (i.e., $\bar{X}_{k}, \bar{T}$, and $\bar{T}^{2}$ ) and hold $\mathrm{CEI}_{i t}$ (equation [2]) at its annual average value (i.e., $\left.\overline{\mathrm{CEI}}_{t}\right)$. Given the estimated $\hat{\alpha}, \hat{\beta}, \hat{\gamma}$, and $\hat{\theta}$, combining equations [1] and [2] and ignoring inefficiency, the annual production frontier can be rewritten as:

$$
\hat{Y}=\overline{\mathrm{CEI}}_{t} \exp \left(\hat{\alpha}+\sum_{k=1}^{6} \hat{\beta}_{k} \ln \bar{X}_{k}+\hat{\theta}_{1} \bar{T}+\hat{\theta}_{2} \bar{T}^{2}\right) .
$$

Thus, equation [5] reflects output variation coming only from annual climatic variability $\overline{\mathrm{CEI}}_{t}$ and this equation is used to generate the results presented in Figure 5.

Scenario analyses has been previously used by several researchers to predict the effect of future climatic conditions on expected agricultural output (e.g., Fisher et al., 2012; Seo, 2012). We applied this type of methodology to calculate expected change in dairy output with respect to future expected temperature and precipitation values while holding other factors at their 2012 level. For example, for year $t^{\prime}$, the expected output $\hat{Y}_{i t^{\prime}}$ of farm $i$ with respect to climatic conditions $Z_{s i t^{\prime}}$, is defined as

$$
\hat{Y}_{i t^{\prime}}=\exp \left(\hat{\alpha}+\sum_{k=1}^{6} \hat{\beta}_{k} \ln X_{k i 2012}+\sum_{s=1}^{8} \hat{\gamma}_{s} Z_{s i t^{\prime}}+\hat{\theta}_{1} 17+\hat{\theta}_{2} 17^{2}\right) .
$$

\section{RESULTS AND DISCUSSION}

The estimated results for models 1 through 5 are presented in Table 3. The null hypothesis that all coefficients are zero was rejected for all models. Furthermore, the estimated coefficients of the 6 conventional inputs were all significant with the expected positive sign and values (i.e., between 0 and 1 ). In the CobbDouglas functional form, these coefficients denote partial input elasticities of production that measure the percent change in output with respect to a $1 \%$ change in the respective input. Dairy herd size was the main input influencing production, a finding consistent with several other papers that have a similar specification (e.g., Bravo-Ureta and Rieger, 1991; Ahmad and Bravo-Ureta, 1995; Mukherjee et al., 2013; Key and Sneeringer, 2014). Concentrate feed was the second most important input when unobserved heterogeneity was included (elasticities are around 0.12 in models 3 to $5)$. In contrast, when heterogeneity was ignored, expenditure on crops was the second most important input (elasticities are around 0.16 in models 1 and 2). These differences suggest that the treatment of heterogeneity in production frontier models deserves attention. The

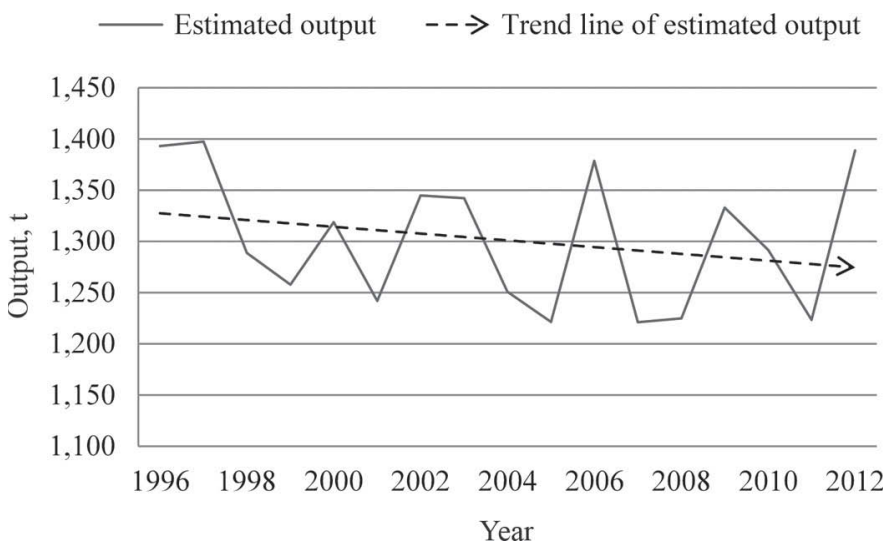

Figure 5. Estimated output change with respect to the annual climatic effect index: 1996-2012. Estimated annual output of the average farm, holding conventional inputs and the time trend at their overall mean values, and the climatic effect index at its annual average value. 
Table 3. Parameter estimates for 5 stochastic production frontier models

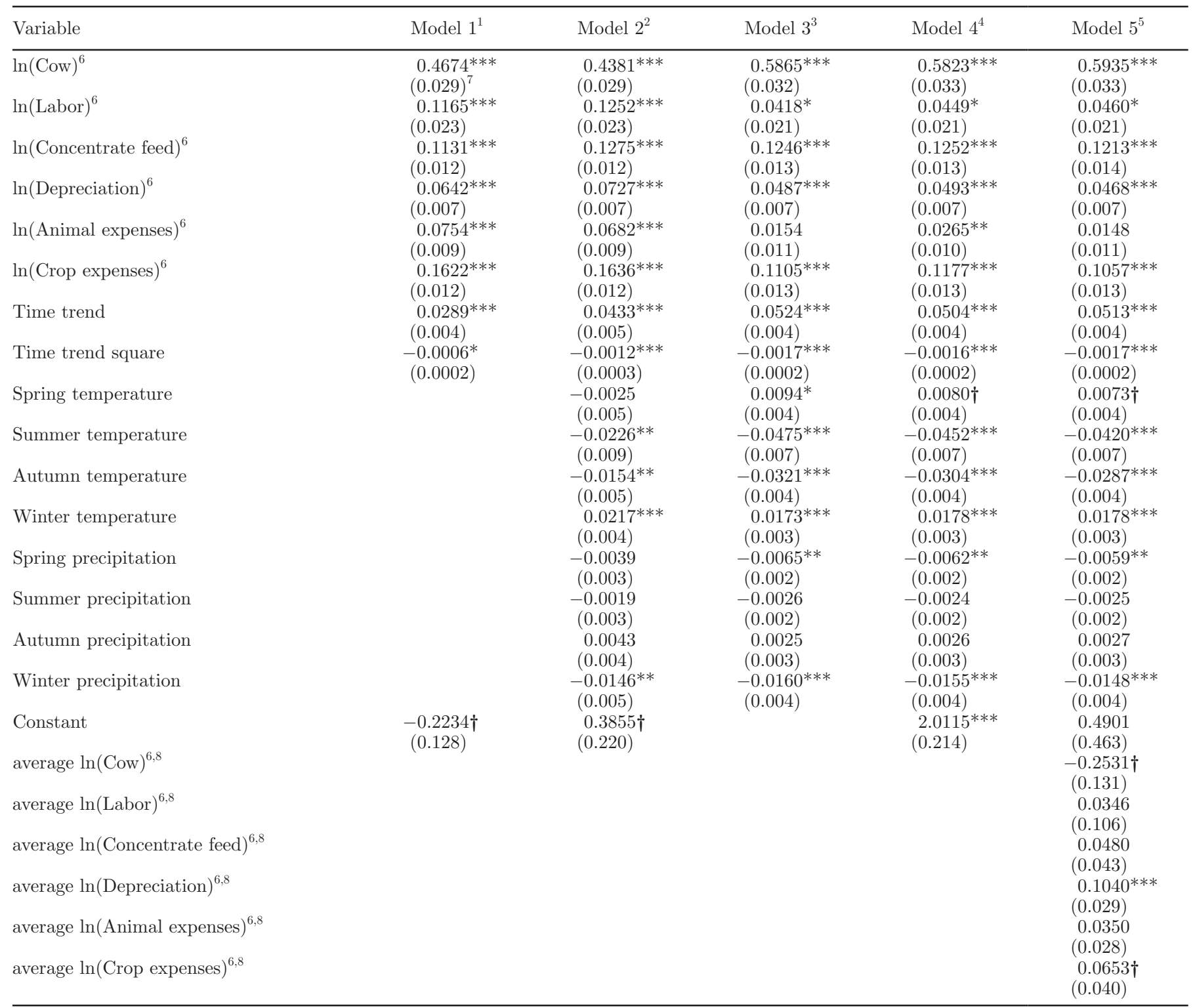

${ }^{1}$ Pooled frontier model without climatic variables.

${ }^{2}$ Pooled frontier model with climatic variables.

${ }^{3}$ "True" fixed effect model with climatic variables.

" "True" random effect model with climatic variables.

${ }^{5}$ "True" random effect model with Mundlak's specification and climatic variables.

${ }^{6} \mathrm{Log}$ value of the conventional inputs.

${ }^{7}$ Standard deviation is presented below the estimated parameter.

${ }^{8}$ Mean value of regressors.

$\dagger P<0.10,{ }^{*} P<0.05,{ }^{* *} P<0.01,{ }^{* * *} P<0.001$.

elasticity of labor in the pooled models was 3 times larger than in the others. Similarly, the coefficients for animal expenditures and capital depreciation were greater in the pooled models compared with the other 3. All models exhibited decreasing returns to scale ranging from 0.99 (model 1) to 0.93 (model 3).
We conducted a likelihood ratio test between model 1 and 2 , and the results led to rejection of the hypothesis that the coefficients of the climatic variables are jointly zero. Thus, climatic variables should be included in the specification of the production frontier model. Turning to the models that included unobserved heterogeneity 
Table 4. Average annual technical efficiency (\%) estimated for each model for 54 Wisconsin dairy farms: $1996-2012$

\begin{tabular}{|c|c|c|c|c|c|}
\hline Year & Model $1^{1}$ & Model $2^{2}$ & Model $3^{3}$ & Model $4^{4,5}$ & Model $5^{6}$ \\
\hline 1996 & 89.63 & 89.41 & 91.19 & 90.75 & 91.24 \\
\hline 1997 & 91.46 & 90.75 & 92.79 & 92.43 & 92.69 \\
\hline 1998 & 88.69 & 88.12 & 92.17 & 91.50 & 91.82 \\
\hline 1999 & 91.13 & 91.59 & 94.75 & 94.36 & 94.55 \\
\hline 2000 & 91.42 & 91.16 & 93.16 & 92.81 & 93.06 \\
\hline 2001 & 88.48 & 88.31 & 91.50 & 90.90 & 91.24 \\
\hline 2002 & 91.09 & 89.27 & 92.06 & 91.55 & 91.87 \\
\hline 2003 & 92.58 & 91.62 & 94.37 & 94.05 & 94.26 \\
\hline 2004 & 87.72 & 87.12 & 90.24 & 89.58 & 90.11 \\
\hline 2005 & 89.63 & 89.52 & 93.41 & 92.91 & 93.09 \\
\hline 2006 & 92.15 & 90.48 & 92.88 & 92.52 & 92.81 \\
\hline 2007 & 86.81 & 87.04 & 90.56 & 89.86 & 90.36 \\
\hline 2008 & 89.66 & 90.84 & 93.34 & 92.98 & 93.23 \\
\hline 2009 & 91.96 & 91.79 & 93.47 & 93.20 & 93.44 \\
\hline 2010 & 89.15 & 88.99 & 91.35 & 90.87 & 91.28 \\
\hline 2011 & 88.97 & 89.38 & 93.32 & 92.79 & 92.98 \\
\hline 2012 & 91.31 & 89.16 & 92.58 & 92.06 & 92.35 \\
\hline Average & 90.11 & 89.68 & 92.54 & 92.07 & 92.38 \\
\hline \multicolumn{6}{|c|}{${ }^{1}$ Pooled frontier model without climatic variables. } \\
\hline \multirow{2}{*}{\multicolumn{6}{|c|}{${ }^{2}$ Pooled frontier model with climatic variables. }} \\
\hline & & & & & \\
\hline \multicolumn{6}{|c|}{ "True" fixed effect model with climatic variables. } \\
\hline \multicolumn{6}{|c|}{ "True" random effect model with climatic variables. } \\
\hline \multicolumn{6}{|c|}{${ }^{5}$ Model 4 provides the most robust result. } \\
\hline
\end{tabular}

and climatic variables, we conducted a Hausman test of model 3 (TFE) versus model 4 (TRE) to examine the null hypothesis that unobserved heterogeneity is independent of the other explanatory variables. The results of this test did not reject the null hypothesis (Hausman test: Prob $>$ chi2 $=0.594$ ), which supports model 4, where unobserved heterogeneity is assumed to be uncorrelated with the other regressors; thus, model 5 (TRE-M) becomes redundant. Moreover, 5 of the 6 coefficients for the group mean regressors were not statistically significant at the 0.05 level or less. Therefore, the discussion that follows is based on model 4.

\section{TE}

Table 4 shows the average annual TE estimated from each model. Average TE for model 4, which was the chosen model, was high, at $92.07 \%$, compared with the results reported in the meta-analyses by Bravo-Ureta et al. (2007) and Moreira and Bravo-Ureta (2010). This number is also higher than the $88 \%$ TE estimated by Cabrera et al. (2010) using a sample of 273 dairy farms in Wisconsin. Average TE for models 3 to 5 were higher than for models 1 and 2 , which is consistent with the fact that the former models separate farm heterogeneity from the TE term. Moreover, this comparison suggests that ignoring heterogeneity between farms may lead to biased estimates.

\section{Estimated Climatic Effects}

The analysis of the climatic effects is the centerpiece of this paper. According to the results of model 4 displayed in Table 3, an increase in spring and winter temperature had a positive effect on output whereas the opposite was noted in summer and autumn. A higher value of precipitation has a significantly negative effect on output in both spring and winter. Specifically, a one-unit increase in temperature $\left(1^{\circ} \mathrm{C}\right)$ led to a $4.52 \%$ reduction in output in summer and to a $3.04 \%$ reduction in autumn. By contrast, a $1^{\circ} \mathrm{C}$ increase led to an output rise equal to $0.8 \%$ in spring and $1.8 \%$ in winter. Precipitation in summer and in autumn did not have a significant effect on dairy output. However, a 1-cm increase in precipitation in spring led to a $0.62 \%$ reduction in output. Precipitation in winter is also harmful, where a $1-\mathrm{cm}$ increase led to a $1.6 \%$ reduction in output.

Table 5 presents the annual average CEI based on equations [2] through [4]. We first computed the CEI terms for each farm $i$ at time $t$ and then aggregated these values to obtain average annual CEI. In the first column, CEI values exhibit a decreasing trend from 1996 to 2012, which implied that climatic conditions for dairy farming in Wisconsin have worsened over that period. The values of CEIT are lower than CEIP, which indicates that temperature had a larger negative effect than precipitation. Regarding the seasonal dimension, 
Table 5. Average annual climatic effect indexes based on the "true" random effect specification (model 4): 1996-2012

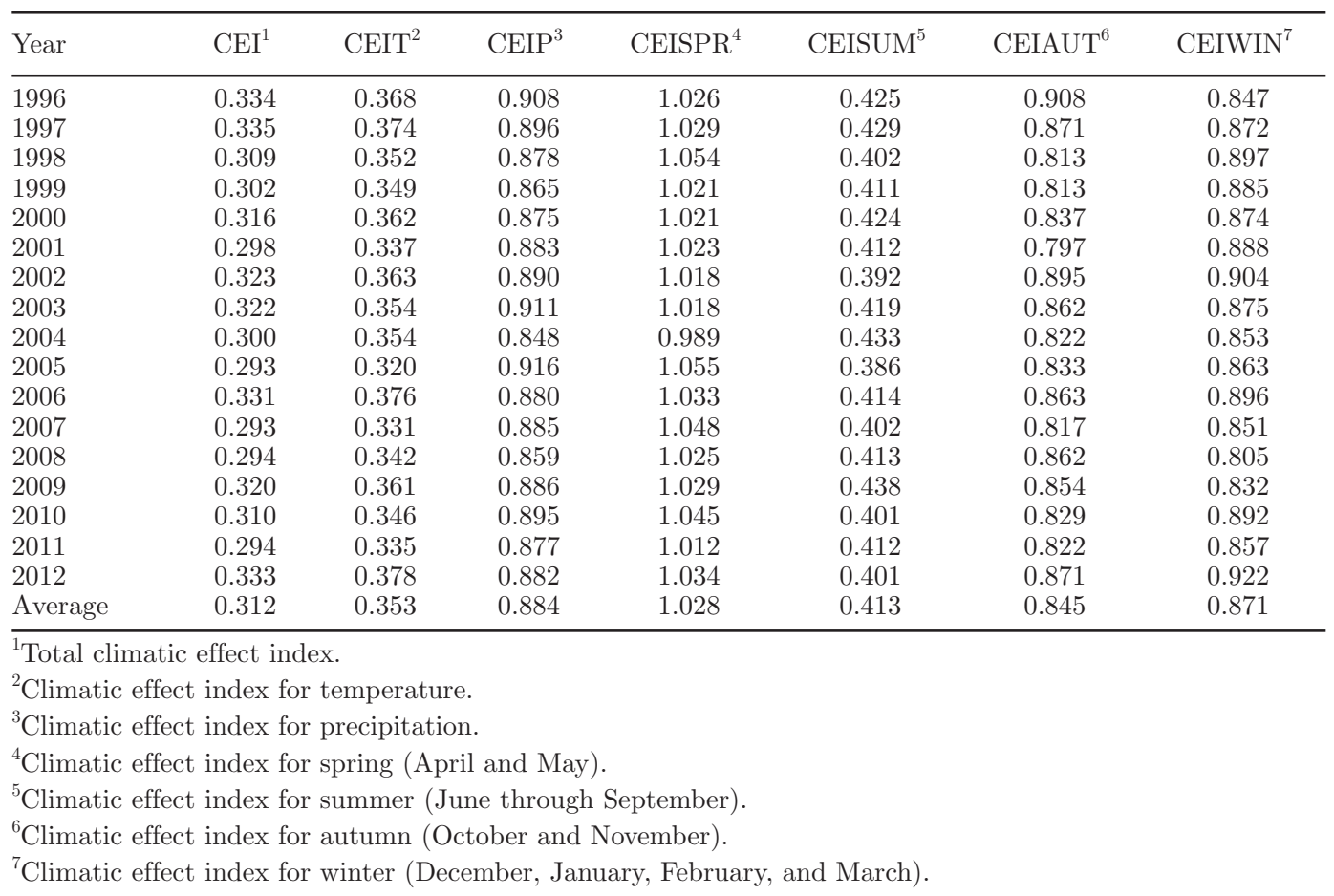

the analysis showed negative average effects on production in summer, autumn, and winter (CEISUM $=0.41$; CEIAUT $=0.85 ;$ CEIWIN $=0.87)$, whereas the effect in spring was positive (CEISPR $=1.03)$. The climatic effect in summer was worse than in autumn and winter.

Estimated output over the $17-\mathrm{yr}$ period studied was calculated using equation [5], and the results are presented in Figure 5. The estimated output showed wide variability and a slight negative trend over time, indicating that climatic effects have gradually led to declines in output holding all else constant.

\section{Scenario Analysis}

Now we turn to the expected effects of alternative projections of future climate change on output. To do this, we simulated the path of output growth under 2 IPCC climatic scenarios over the period from 2020 to 2039, using 2012 as the baseline, and assuming the value of inputs and the time trend are fixed at 2012 levels. The CEI was calculated based on equation [2]. The baseline output was equivalent to the actual average output in 2012, whereas the predicted output was calculated using equation [6]. Again, the data revealed a slight negative trend in future milk production. Then, given the projected values for temperature and precipitation based on the CMT and HA2 scenarios, we calculated the CEI and then projected output for the period 2020 to 2039. The results are shown in Table 6 .
Under the 2 IPCC scenarios, most of the predicted output values were lower than the baseline (except for years 2020, 2028, 2029, and 2035), which means that climatic conditions for dairy production would worsen in the future. On average, the CEI value in the CMT scenario (average CEI $=0.295$ ) was higher than the HA2 scenario (average CEI $=0.275$ ) suggesting, as would be expected, that more extreme climate change would be more harmful to dairy production compared with a more moderate scenario. Under the CMT scenario, the highest value of CEI was 0.33 in the year 2029 and the lowest was 0.26 in 2030. Thus, the best climatic condition would happen in 2029 and the worst in 2030 if climate change is moderate. Under the HA2 scenario, the highest value of CEI is 0.32 in the year 2028 , and the lowest is 0.23 in 2035 . Thus, if climate change is more severe, the best climatic conditions will occur in 2028 and the worst is in 2035.

Output was expected to vary considerably with climate change. In the near future, on average, climate change would lead to a decrease in dairy output equal to $4.53 \%$ under the CMT scenario and to $10.98 \%$ under the HA2 scenario. Under the CMT scenario, better conditions in 2020, 2028, 2029, and 2035 would increase output between 0.34 and $5.12 \%$. For the other years, output would vary between -16.35 and $-0.98 \%$ compared with the baseline. For the HA2 scenario, climatic conditions would have a uniformly negative effect on output except for 2028, and the output fluctuation was 
Table 6. Projected annual average climatic effect index and output under 2 IPCC scenarios based on the "true" random effect specification (model 4): 2020-2039

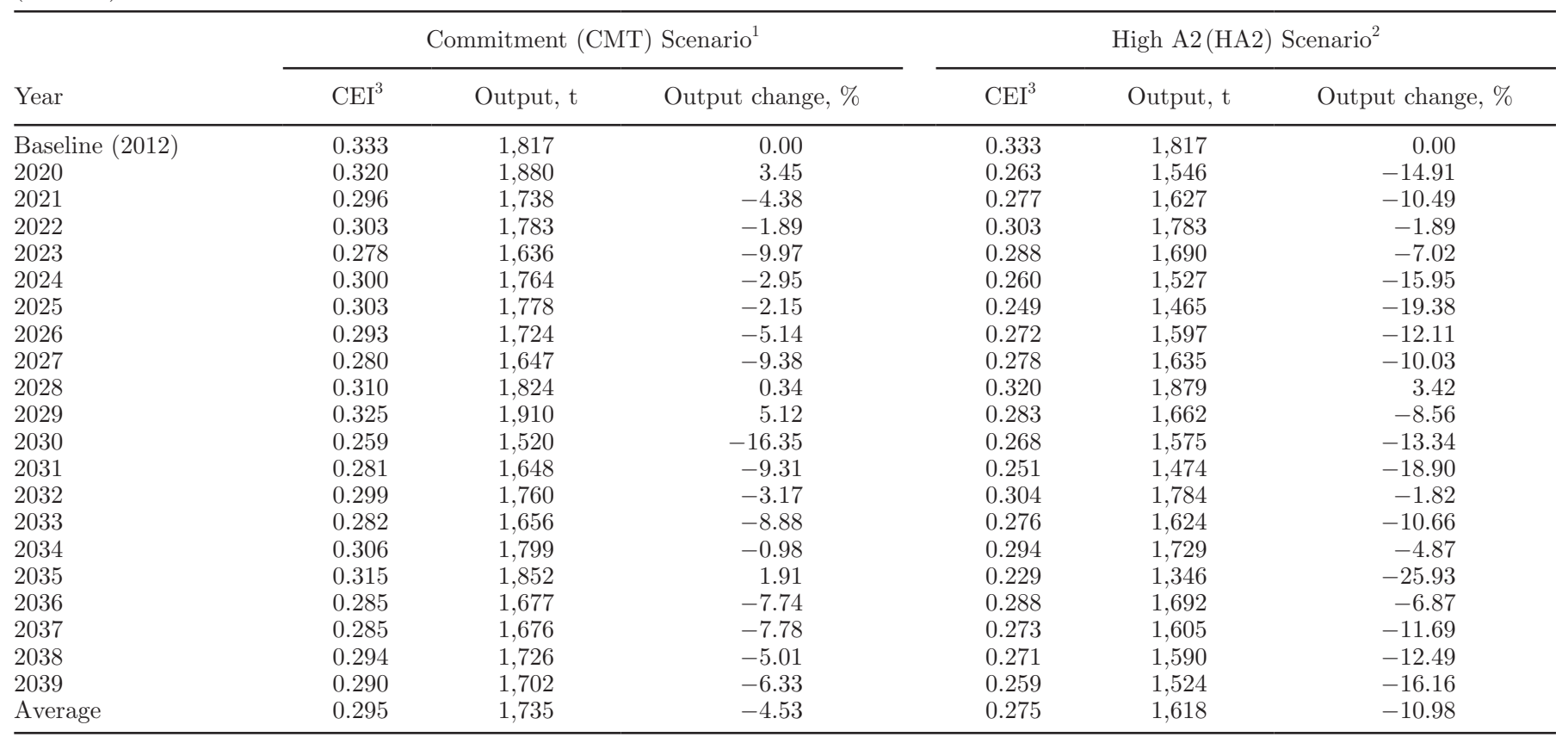

${ }^{1}$ Commitment scenario assumes that the concentration of pollutants in the atmosphere is held fixed at 2000 levels. Data are derived from the National Center for Atmospheric Research (NCAR) GIS program (https://gisclimatechange.ucar.edu/).

${ }^{2}$ High A2 scenario assumes that the world undergoes high population growth, medium gross domestic product growth, high energy use, mediumhigh land use changes, low resource availability (mainly oil and gas), and slow technological change. Data are derived from the National Center for Atmospheric Research (NCAR) GIS program (https://gisclimatechange.ucar.edu/).

${ }^{3}$ Total climatic effect index.

between -25.93 and $-1.89 \%$. The best year would be 2028 , with a $3.42 \%$ increase in milk production. Thus, these results indicate that climate change would have a significant effect on future dairy production.

\section{CONCLUSIONS}

This paper contributes to the literature by introducing 8 climatic variables into alternative stochastic production frontier models to then derive measures of climatic effects. The results reveal that higher summer temperatures are harmful, warmer winters are beneficial, and higher precipitation is consistently deleterious for dairy production in Wisconsin. The results also suggest that, holding all other factors constant, a mild negative association exists between climatic effects and dairy farm output over the 17-yr period analyzed. A scenario analysis indicates that climate change can be expected to induce reductions in future dairy production. Thus, research and extension efforts are needed to promote suitable adaptation strategies. As is common in the economics literature, we assumed that the production frontier parameters remain constant during the forecast period, which could be a strong assump- tion. Thus, predicting the possible evolution of these parameters over time would be a valuable focus in future studies.

\section{ACKNOWLEDGMENTS}

This work was partially funded by Grant \#201167024-30912, Agricultural Food Research Initiative of the National Institute of Food and Agriculture, USDA. We thank David Roibás, 2 anonymous reviewers, and the editor for their helpful comments.

\section{REFERENCES}

Abdulai, A., and H. Tietje. 2007. Estimating technical efficiency under unobserved heterogeneity with stochastic frontier models: Application to northern German dairy farms. Eur. Rev. Agric. Econ. 34:393-416.

Ahmad, M., and B. E. Bravo-Ureta. 1995. An econometric decomposition of dairy output growth. Am. J. Agric. Econ. 77:914-921.

Allen, J. D., S. D. Anderson, R. J. Collier, and J. F. Smith. 2013 Managing heat stress and its impacts on cow behavior. Page 150-162 in Proc. West. Dairy Manag. Conf., Reno, NV. Accessed Sep. 15, 2015. http://www.wdmc.org/2013/2013\%20WDMC\%20 Proceedings\%20-\%20All\%20Combined.pdf.

Battese, G. E., and T. J. Coelli. 1988. Prediction of firm-level technical efficiencies with a generalized frontier production function and panel data. J. Econom. 38:387-399. 
Battese, G. E., and T. J. Coelli. 1992. Frontier production functions, technical efficiency and panel data: With application to paddy farmers in India. J. Prod. Anal. 3:153-169.

Bravo-Ureta, B. E., and L. Rieger. 1991. Dairy farm efficiency measurement using stochastic frontiers and neoclassical duality. Am. J. Agric. Econ. 73:421-428.

Bravo-Ureta, B. E., D. Solís, V. H. Moreira, J. F. Maripani, A. Thiam, and T. E. Rivas. 2007. Technical efficiency in farming: A metaregression analysis. J. Prod. Anal. 27:57-72.

Brody, S. 1956. Climatic physiology of cattle. J. Dairy Sci. 39:715-725.

Cabrera, V. E. D. Solís, and J. Del Corral. 2010. Determinants of technical efficiency among dairy farms in Wisconsin. J. Dairy Sci. 93:387-393.

Collier, R. J., R. B. Zimbelman, R. P. Rhoads, M. L. Rhoads, and L. H. Baumgard. 2011. A re-evaluation of the impact of temperature humidity index (THI) and black globe humidity index (BGHI) on milk production in high producing dairy cows. Page 113-125 in Proc. West. Dairy Manag. Conf., Reno, NV. Accessed Sep. 15, 2015. http://www.wdmc.org/2011/2011\%20ProceedingsComplete.pdf.

Cook, N. B., R. L. Mentink, T. B. Bennett, and K. Burgi. 2007. The effect of heat stress and lameness on time budgets of lactating dairy cows. J. Dairy Sci. 90:1674-1682.

Dell, M., B. F. Jones, and B. A. Olken. 2014. What do we learn from the weather? The new climate-economy literature. J. Econ. Lit. 52:740-798.

Deschenes, O., and M. Greenstone. 2007. The economic impacts of climate change: Evidence from agricultural output and random fluctuations in weather. Am. Econ. Rev. 97:354-385.

Fisher, A. C., W. M. Hanemann, M. J. Roberts, and W. Schlenker. 2012. The economic impacts of climate change: Evidence from agricultural output and random fluctuations in weather: Comment. Am. Econ. Rev. 102:3749-3760.

Fried, H. O., C. K. Lovell, and S. S. Schmidt. 2008. The Measurement of Productive Efficiency and Productivity Growth. Oxford University Press. New York, NY.

Greene, W. 2005a. Fixed and random effects in stochastic frontier models. J. Prod. Anal. 23:7-32.

Greene, W. 2005b. Reconsidering heterogeneity in panel data estimators of the stochastic frontier model. J. Econom. 126:269-303.

Greene, W. 2008. Econometric Analysis. 6th ed. Prentice Hall, Englewood Cliffs, NJ.

Hausman, J. A. 1978. Specification tests in econometrics. Econometrica $46: 1251-1271$.

Hill, M. J., G. E. Donald, M. W. Hyder, and R. C. Smith. 2004 Estimation of pasture growth rate in the south west of Western Australia from AVHRR NDVI and climate data. Remote Sens. Environ. 93:528-545

Holter, J. B., J. W. West, M. L. McGilliard, and A. N. Pell. 1996 Predicting ad libitum dry matter intake and yields of Jersey cows. J. Dairy Sci. 79:912-921.

Hughes, N., K. Lawson, A. Davidson, T. Jackson, and Y. Sheng. 2011 Productivity pathways: Climate-adjusted production frontiers for the Australian broadcare cropping industry. ABARES research report 11.5, Canberra.

IPCC. 2014. Climate Change 2014: Impacts, Adaptation, and Vulnerability. Contribution of Working Group II to the Fifth Assessment Report of the Intergovernmental Panel on Climate Change. Cambridge Univ Press, Cambridge, UK.

Kadzere, C. T., M. R. Murphy, N. Silanikove, and E. Maltz. 2002. Heat stress in lactating dairy cows: A review. Livest. Prod. Sci. 77:59-91

Kelly, D. L., C. D. Kolstad, and G. T. Mitchell. 2005. Adjustment costs from environmental change. J. Environ. Econ. Manage. 50:468-495.

Key, N., and S. Sneeringer. 2014. Potential effects of climate change on the productivity of US dairies. Am. J. Agric. Econ. 96:1136-1156.

Kumbhakar, S. C., and E. G. Tsionas. 2006. Estimation of stochastic frontier production functions with input-oriented technical efficiency. J. Econom. 133:71-96.
Lawson, L. G., J. F. Agger, M. Lund, and T. Coelli. 2004. Lameness, metabolic and digestive disorders, and technical efficiency in Danish dairy herds: A stochastic frontier production function approach. Livest. Prod. Sci. 91:157-172.

Mader, T. L. 2003. Environmental stress in confined beef cattle. J. Anim. Sci. 81:E110-E119.

Mayen, C. D., J. V. Balagtas, and C. E. Alexander. 2010. Technology adoption and technical efficiency: Organic and conventional dairy farms in the United States. Am. J. Agric. Econ. 92:181-195.

Mendelsohn, R., W. D. Nordhaus, and D. Shaw. 1994. The impact of global warming on agriculture: A Ricardian analysis. Am. Econ. Rev. 84:753-771.

Moreira, V. H., and B. E. Bravo-Ureta. 2010. Technical efficiency and metatechnology ratios for dairy farms in three southern cone countries: A stochastic meta-frontier model. J. Prod. Anal. 33:33-45.

Mukherjee, D. 2012. Agricultural sustainability in the face of climatic change: challenges and opportunities. PhD diss. University of Connecticut, Storrs.

Mukherjee, D., B. E. Bravo-Ureta, and A. de Vries. 2013. Dairy productivity and climatic conditions: Econometric evidence from southeastern United States. Aust. J. Agric. Resour. Econ. 57:123140.

Mundlak, Y. 1978. On the pooling of time series and cross section data. Econometrica 46:69-85.

Nardone, A., B. Ronchi, N. Lacetera, M. S. Ranieri, and U. Bernabucci. 2010. Effects of climate changes on animal production and sustainability of livestock systems. Livest. Sci. 130:57-69.

NRC. 2001. Nutrient Requirements of Dairy Cattle. 7th rev ed. Natl. Acad. Sci., Washington, DC.

Njuki, E., and B. E. Bravo-Ureta. 2015. The economic costs of environmental regulation in US dairy farming: A directional distance function approach. Am. J. Agric. Econ. 97:1087-1106. http:// dx.doi.org/10.1093/ajae/aav007.

Njuki, E., B. E. Bravo-Ureta, and C. J. O'Donnell. 2015. A new look at the decomposition of agricultural productivity growth incorporating climatic effects. Working Paper. University of Connecticut, Storrs.

Rhoads, M. L., R. P. Rhoads, M. J. VanBaale, R. J. Collier, S. R Sanders, W. J. Weber, B. A. Crooker, and L. H. Baumgard. 2009. Effects of heat stress and plane of nutrition on lactating Holstein cows: I. Production, metabolism, and aspects of circulating somatotropin. J. Dairy Sci. 92:1986-1997.

Roenfeldt, S. 1998. You can't afford to ignore heat stress. Dairy Manag. 35:6-12.

Schlenker, W., W. M. Hanemann, and A. C. Fisher. 2006. The impact of global warming on US agriculture: An econometric analysis of optimal growing conditions. Rev. Econ. Stat. 88:113-125.

Seo, S. N. 2012. Adaptation behaviours across ecosystems under global warming: A spatial micro-econometric model of the rural economy in South America. Pap. Reg. Sci. 91:849-871.

Seo, S. N., and R. Mendelsohn. 2008. Measuring impacts and adaptations to climate change: A structural Ricardian model of African livestock management. Agric. Econ. 38:151-165.

St-Pierre, N. R., B. Cobanov, and G. Schnitkey. 2003. Economic losses from heat stress by US livestock industries. J. Dairy Sci. 86:E52E77.

Tauer, L. W., and A. K. Mishra. 2006. Dairy farm cost efficiency. J. Dairy Sci. 89:4937-4943.

Theodoridis, A. M., and A. Psychoudakis. 2008. Efficiency measurement in Greek dairy farms: Stochastic frontier vs. data envelopment analysis. Int. J. Econ. Sci. Appl. Res. 2:53-66.

Tucker, C. B., A. R. Rogers, and K. E. Shutz. 2007. Effect of solar radiation on dairy cattle behavior, use of shade and body temperature in a pasture-based system. Appl. Anim. Behav. Sci. 109:141-154.

USDA National Agricultural Statistics Service (NASS). 2012. Census of Agriculture, Ag Census Web Maps. Accessed Jan. 29, 2015. http://www.agcensus.usda.gov/Publications/2012/index.php.

US Environmental Protection Agency (EPA). 2013. Future climate change. Accessed Jan. 14, 2014. http://www.epa.gov/climatechange/science/future.html. 
West, J. W. 2003. Effects of heat-stress on production in dairy cattle. J. Dairy Sci. 86:2131-2144.

Young, B. A. 1981. Cold stress as it affects animal production. J. Anim. Sci. 52:154-163.

\section{APPENDIX}

\section{Model Specification}

Based on equation [1] in the body of the paper, the key features of the 5 alternative model (models 1 to 5 ) specifications considered are briefly presented below.

Model 1: Pooled SPF Model Without Climatic Variables. In this model, all observations are pooled as if the data were cross-sectional. This model, which provides a benchmark specification, can be written as:

$$
\ln Y_{i t}=\alpha+\sum_{k=1}^{6} \beta_{k} \ln X_{k i t}+\theta_{1} T+\theta_{2} T^{2}+\nu_{i t}-\mu_{i t} .
$$

Model 2: Pooled SPF Model with Climatic Variables. Model 2 incorporates climatic variables to model 1, which becomes:

$\ln Y_{i t}=\alpha+\sum_{k=1}^{6} \beta_{k} \ln X_{k i t}+\sum_{s=1}^{8} \gamma_{s} Z_{s i t}+\theta_{1} T+\theta_{2} T^{2}+\nu_{i t}-\mu_{i t}$.

Thus, models 1 and 2 make it possible to test the null hypothesis that climatic effects are not relevant (i.e., $\mathrm{H}_{0}: \gamma_{1}=\gamma_{2}=\gamma_{3}=\gamma_{4}=\gamma_{5}=\gamma_{6}=\gamma_{7}=\gamma_{8}=0$ ).

Model 3: "True" Fixed Effects Model with Climatic Variables. Models 1 and 2 ignore possible unobserved heterogeneity, which can lead to biased estimates. Model 3 incorporates the term $\alpha_{i}$ to the SPF to capture a farm-specific fixed effects and is written as

$\ln Y_{i t}=\alpha_{i}+\sum_{k=1}^{6} \beta_{k} \ln X_{k i t}+\sum_{s=1}^{8} \gamma_{s} Z_{s i t}+\theta_{1} T+\theta_{2} T^{2}+\nu_{i t}-\mu_{i t}$.

This model can be estimated by maximizing the unconditional log-likelihood function directly (Greene, 2005b).
Model 4: "True" Random Effects Model with Climatic Variables. This model incorporates a heterogeneity term $w_{i} \sim \operatorname{iidN}\left(0, \sigma_{w}^{2}\right)$ to the $\mathrm{SPF}$, which is randomly distributed and is assumed to be uncorrelated with all other regressors. It is specified as:

$$
\begin{aligned}
& \ln Y_{i t}=\alpha+w_{i}+\sum_{k=1}^{6} \beta_{k} \ln X_{k i t}+\sum_{s=1}^{8} \gamma_{s} Z_{s i t}+\theta_{1} T+ \\
& \theta_{2} T^{2}+\nu_{i t}-\mu_{i t} .
\end{aligned}
$$

Equation [A4] can be treated as a standard SPF model with random intercepts. Then, the Hausman test (Hausman, 1978; Greene, 2008) was used to evaluate the hypothesis of independence of farm-specific heterogeneity and other variables.

Model 5: "True" Random Effects Model with the Mundlak Specification and Climatic Variables. Abdulai and Tietje (2007), following the Mundlak (1978) method, redefine the heterogeneity term $w_{i}$ as a function of the mean of each regressor:

$$
w_{i}=\sum_{k=1}^{6} \delta_{k} \ln \bar{X}_{k i}+\bar{m}_{i},
$$

where $\ln \bar{X}_{k i}$ represents an average of the $\log$ value of the $k$ th regressor over time for farm $i$, and $\bar{m}_{i} \sim \operatorname{iidN}\left(0, \sigma_{\bar{m}}^{2}\right)$ is uncorrelated with all other regressors. Thus, the model can be written as:

$$
\begin{aligned}
& \ln Y_{i t}=\alpha+\bar{m}_{i}+\sum_{k=1}^{6} \beta_{k} \ln X_{k i t}+\sum_{s=1}^{8} \gamma_{s} Z_{s i t}+ \\
& \sum_{k=1}^{6} \delta_{k} \ln \overline{\mathrm{X}}_{k i}+\theta_{1} T+\theta_{2} T^{2}+\nu_{i t}-\mu_{i t} .
\end{aligned}
$$

Equations [A4] and [A6] can be estimated using a maximum simulated likelihood (Greene, 2005b). 